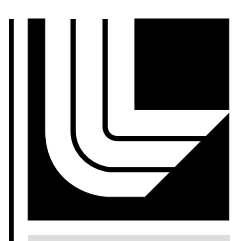

LLNL-TR-577712

LA W REN CE LIVERMORE N A TIO NAL LABORATORY

Analysis of the Band Gap Type Dataset

C. Kamath

August 29, 2012 
This document was prepared as an account of work sponsored by an agency of the United States government. Neither the United States government nor Lawrence Livermore National Security, LLC, nor any of their employees makes any warranty, expressed or implied, or assumes any legal liability or responsibility for the accuracy, completeness, or usefulness of any information, apparatus, product, or process disclosed, or represents that its use would not infringe privately owned rights. Reference herein to any specific commercial product, process, or service by trade name, trademark, manufacturer, or otherwise does not necessarily constitute or imply its endorsement, recommendation, or favoring by the United States government or Lawrence Livermore National Security, LLC. The views and opinions of authors expressed herein do not necessarily state or reflect those of the United States government or Lawrence Livermore National Security, LLC, and shall not be used for advertising or product endorsement purposes.

This work performed under the auspices of the U.S. Department of Energy by Lawrence Livermore National Laboratory under Contract DE-AC52-07NA27344. 


\title{
Analysis of the Band Gap Type Dataset
}

\author{
Chandrika Kamath \\ kamath2@llnl.gov \\ Lawrence Livermore National Laboratory
}

August 24, 2012

\section{Introduction}

This report summarizes the work done as part of the MINDES: Data Mining for Inverse Design project [3] to mine the datasets generated by the Center for Inverse Design [1], an Energy Frontier Research Center (EFRC) of the Office of Science, US Department of Energy. In the course of the MINDES project, two datasets were analyzed, one on the formation enthalpy of spinels, and the other on the band gap type of the class of ternary compounds generated at NREL; the latter is the focus of this report.

The dataset considered in this analysis is from computer simulations of ternary compounds. Given the composition of a compound, that is, the three elements and their percentages in the compound, the simulations calculate various quantities, and associate with each compound a band gap type, which can take values $1,2,3$, or 4 . The primary focus of the analysis was to determine which properties of the elements are associated with band gap type 1 compounds, which are potentially more useful as photovoltaic material. Any insights obtained on the other band gap types in the course of the analysis were also deemed to be of interest. Further, it is expected that the insights gained in the course of this study will also apply when attempting to correlate other physical properties of compounds to their individual constituents.

This analysis falls in the broad area of design of computer experiments [2], where an ensemble of simulations is used to guide physical experiments and gain insights into the design space which maps the inputs of the simulations to the output(s). As the simulations are often computationally expensive, the ensemble must be carefully designed to gain the greatest insights into the physical phenomenon of interest using as few simulations as possible. A possible solution is to consider an incremental approach where we analyze the input/output data from the simulations that have already been run to identify the next set of simulations such that these new simulations would add the greatest insights, by either refining the original data set in a region of interest, or exploring new regions in the design space.

Therefore, in the context of our problem, we can analyze the simulations that have been run thus far to understand what properties of the elements comprising a compound are relevant to the band gap of type 1. By combining this information with physics insights, we can suitably create other compounds and expect that their simulation will likely indicate the compounds to be of band gap type 1 . 
In this report, we start by describing the dataset in Section 2, followed by the initial exploratory analysis of the data in Section 3. The detailed analysis of the data to gain insights into band gap type 1 compounds is described in Section 4, followed by Section 5 which provides other insights into the data, including an analysis of band gap types 2,3 , and 4 . We conclude with a brief summary and some thoughts for future work.

Disclaimer - This report is written from the point of view of a data miner, not a materials scientist, a physicist, or a chemist. The analysis is purely data driven and is not influenced by any domain-specific biases. Also, any conclusions drawn must be interpreted with care as the analysis reflects the characteristics and quality of the data provided; the availability of additional data may change the results.

\section{Description of the data}

The data were provided in the form of a table, consisting of 487 compounds (also referred to as instances), each described by 83 features (see Table 3 in Appendix A). Of these 83 features, 3 are the atomic species (i.e., elements) that make up the compound, referred to as "A", "B", and "C"; 3 are the compositions of each species (the values are all less than 1.0 and sum to 1.0), referred to as "p", "q", and "r"; and 3 are other variables ("E1", "E4", and "sg"). "sg" is the space group, reflecting the crystal symmetry and "E1" and "E4" are properties of the compound. Since our goal is to use the properties of the atomic species to predict the gap type of the compound, we ignore features E1 and E4. Of the remaining 74 features, 25 describe species A, 23 describe species B, and 26 describe species C.

Associated with each compound is the gaptype, which takes on values 1 through 4 . Of the 487 instances, 76 are of gaptype 1 (15.6\%), 100 of gaptype 2 (20.5\%), 133 of gaptype $3(27.3 \%)$, and 178 of gaptype $4(36.6 \%)$.

Observation: In the context of our analysis, this is an unbalanced data set as the percentage of gap type 1 compounds is quite small. This can make it difficult to ascertain if an observation is a physics insight or simply the result of too few samples.

We also observe that the dataset does not include the same set of properties for each of the three species as some properties are unavailable for some elements. Table 4 in Appendex A lists each of the three species A, B, and C, and the properties that are available for them.

An analysis of the features indicated that, for a compound, each feature was generated by taking the value of a property of the element and weighting it by its composition. This meant that if a compound had a certain element, say Ax, occurring at species "A", at a composition of 0.25 , then the features corresponding to "A" for that compound would be the same as the " $\mathrm{A}$ " features for any other compound which also had Ax occurring at species "A" at a composition of 0.25 .

Observation: This approach to generating features from the properties results in several repeating values, which can cause problems with some algorithms. It is also unclear if these features appropriately represent the characteristics that determine the band gap type of a compound. In other words, does the current representation of a compound capture what distinguishes one band type from another, or should we also consider a different representation? 


\section{Exploratory analysis}

The first step in the analysis was to explore the data to check for inaccuracies or errors, and to evaluate the quality of the data for the task at hand. This resulted in the following observations:

- We found one compound, of gap type 2, whose space group was not listed. This was removed, resulting in 486 instances in the dataset.

- We found two pairs of instances which were exact duplicates. Since this was a small number, these instances were not removed from the dataset.

- We found five pairs of compounds which had the same values of "A", "B", "C", "p", "q", "r", and sg, but different band gap types (as well as different E1 and E4 values). These pairs indicate that the dataset contains multiple instances of compounds with the same composition and space group, but different crystal structure. These pairs, their line numbers in the original data file, and their key features are:

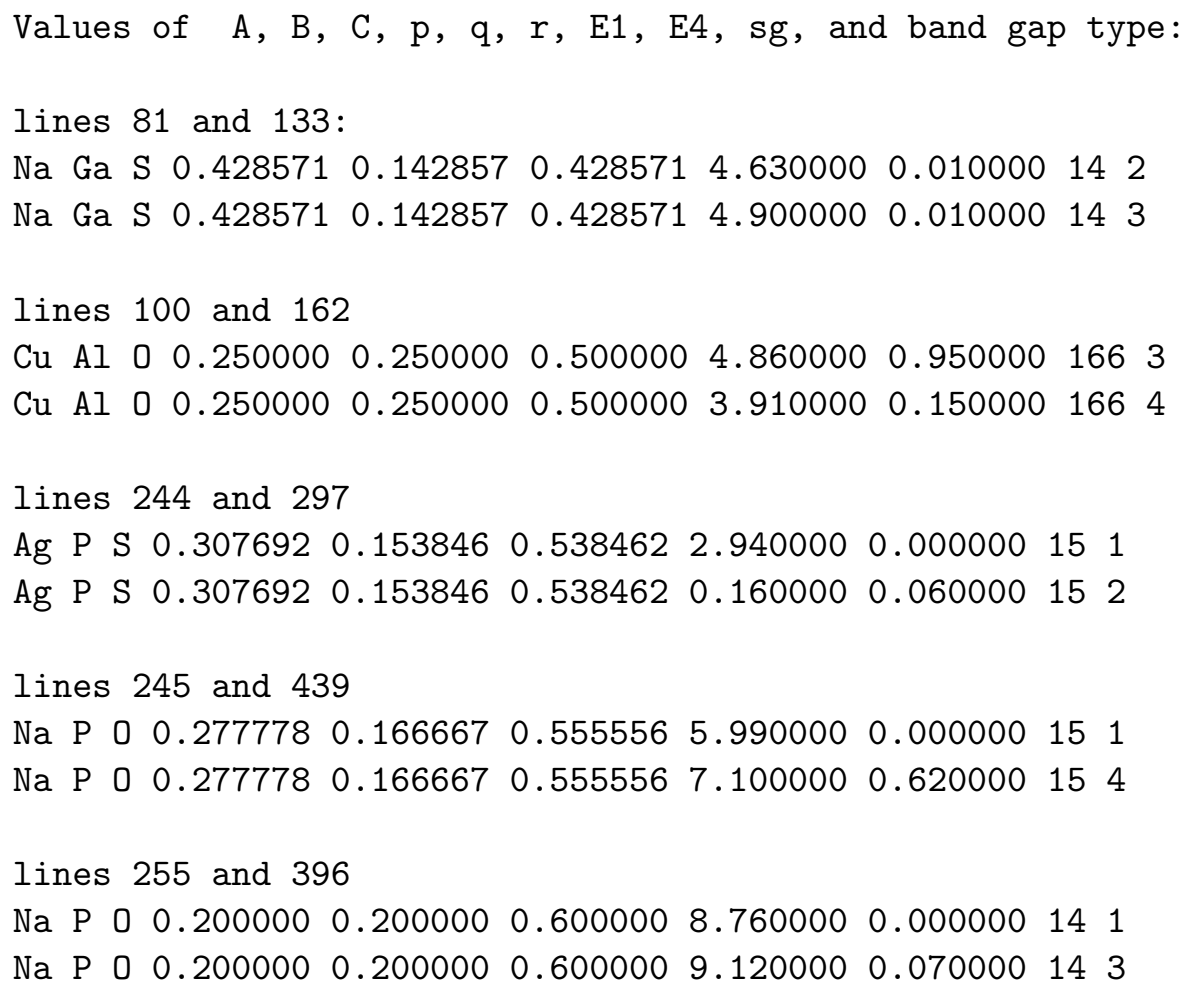

Since "A", "B", "C", "p", "q", and "r" determine the features that are derived from the properties of the elements, this inconsistency indicates that some important features related to the crystal structure are missing from the dataset. This is also supported by the fact that the values of E1 and E4 are different for the five pairs listed above.

- We observed that there are compounds with same values of "A", "B", "C", "p", "q", and "r", but different sg and band gap types. This indicates that sg is likely an important feature in determining the gap type. See Sections 4 and 5 for more details. 


\begin{tabular}{|c|c|c|c|c|c|}
\hline \multicolumn{2}{|c|}{ Species A } & \multicolumn{2}{c|}{ Species B } & \multicolumn{2}{c|}{ Species C } \\
\hline Element & Count & Element & Count & Element & Count \\
\hline $\mathrm{Ag}$ & 75 & $\mathrm{Al}$ & 42 & $\mathrm{~S}$ & 130 \\
$\mathrm{Cu}$ & 86 & $\mathrm{Ga}$ & 42 & $\mathrm{Se}$ & 108 \\
$\mathrm{~K}$ & 76 & $\mathrm{In}$ & 50 & $\mathrm{Te}$ & 46 \\
$\mathrm{Li}$ & 59 & $\mathrm{~B}$ & 36 & $\mathrm{O}$ & 202 \\
$\mathrm{Na}$ & 87 & $\mathrm{Y}$ & 24 & & \\
$\mathrm{Rb}$ & 50 & $\mathrm{Tl}$ & 23 & & \\
$\mathrm{Cs}$ & 53 & $\mathrm{Sc}$ & 14 & & \\
& & $\mathrm{Ta}$ & 24 & & \\
& & $\mathrm{Bi}$ & 30 & & \\
& & $\mathrm{P}$ & 38 & & \\
& & $\mathrm{As}$ & 36 & & \\
& & $\mathrm{Sb}$ & 72 & & \\
& & $\mathrm{Nb}$ & 23 & & \\
& & $\mathrm{~V}$ & 32 & & \\
\hline
\end{tabular}

Table 1: Counts of the different elements that are used for species " $A$ ", "B", and "C". Note that the elements do not overlap, that is, an element appears only in one of the three columns.

- Table 1 lists the elements used for "A", "B", and "C" and the number of times each element is used in the dataset. Note that the three groups do not overlap, that is, an element is never used for species " $\mathrm{A}$ " in one compound and in species " $\mathrm{B}$ " or " $\mathrm{C}$ " in another compound. Note also that elements for species "A" are from columns 1 and 11 of the periodic table; elements for species "B" are from columns 3, 5, 13, and 15 of the periodic table; and elements for species "C" are from column 16 of the periodic table

Observation: When we consider the 76 instances of band gap type 1, we found that certain species occur rarely in certain locations. For example, for the element in species "B", there is one instance with $\mathrm{V}$, two with $\mathrm{Nb}$, and three with $\mathrm{Y}$ and Ta. Similarly, for the element in species "A", there are only three instances with Rb. This may be a reflection of the dataset, or an indication that certain elements in certain locations are unlikely to result in a compound of band gap type 1 .

\section{Detailed analysis for band gap type 1}

Based on the exploratory analysis, there are several factors which make the analysis of band gap type 1 difficult, including:

- the relatively small percentage $(15.6 \%)$ of instances with band gap type 1 ,

- the inconsistency in the dataset, where compounds with the same composition and space group can have different band gap types, and 


\begin{tabular}{|l|l|l|}
\hline Property (to keep) & for species & while removing the following correlated properties \\
\hline pauling & A, C & mulliken_jaffe, sanderson \\
pauling & A & bulk_modulus \\
single_bond_radius & B, C & triple_bond_radius \\
pauling & C & allen \\
atomic_number & A, B, and C & atomic_weight \\
single_bond_radius & A, B, and C & orbital_radii_p, orbital_radii_s, covalent_radius, dou- \\
& Ale_bond_radius, atomic_radius \\
pauling & And C & ionization_energies_1, pettifor, allred_chow \\
\hline
\end{tabular}

Table 2: Identifying the properties to remove as they are highly correlated to other properties which are included in the analysis. See also Table 4.

- the approach used to generate the features from the properties of the elements forming the compound. Since there are few elements used in species "A", "B" and "C", and a limited number of values for "p", "q" and "r", there are compounds with different band gap types but the same values for certain features. This repetition in feature values causes problems with some classification algorithms, such as decision trees.

Based on these observations, we expect that a straightforward application of analysis tools is unlikely to yield insights into band gap type 1 compounds. This was confirmed when we analyzed the data using parallel plots - we did not find any of the features discriminating and there appeared to be little difference between the compounds belonging to the four gap types. Further, as expected, a decision tree classifier was not be able to automatically classify compounds of band gap type 1 with a low error rate.

Given this, we next considered three avenues of exploration:

- First, we reduced the number of features by removing those that were correlated (see Table 4 in Appendix A). We take a conservative approach, removing a property Y only if it is correlated to another property $\mathrm{Z}$ for each of the atomic species for which values are available. Table 2 lists the properties that are retained for each species and the ones that are removed as their correlation coefficient with a property that is retained is greater than 0.9 .

- Second, we considered alternate ways of representing the data derived from the original set of features. This included (i) using properties of the elements directly, without weighting them by the percentages (referred to by the prefix $\mathrm{AU}, \mathrm{BU}$, and $\mathrm{CU}$ to indicate unscaled values); (ii) taking ratios of the properties which are available for all three species (referred to by the prefix ABR, BCR, and ACR); (iii) taking ratios of the unscaled properties which are available for all three species (referred to by the prefix ABUR, BCUR, and ACUR); (iv) taking differences of the properties available for all three species (referred to by the prefix ABD, BCD, and ACD); and (v) taking differences of the unscaled properties available for all three species (referred to by the prefix ABUD, BCUD, and ACUD). Thus, the feature ABURmelting_point represents the ratio of the 
unscaled melting points of the elements for species "A" and "B", where the original values, which had been scaled by the relative percentages of the two species in the original dataset, are now unscaled.

Note that these alternate representations use properties which are available for all the three species, so properties such as density and van der Waal's radius are not included (see Table 4 in Appendix A). The data without the correlated features and with only features available for all three species is referred to as the "cleaned" feature set.

- Third, we tried to determine if, using the new features above, we could identify parts of feature space where a large percentage of points were likely to be of band gap type 1 .

To ensure that the "rules" which identify parts of feature space with a large percentage of type 1 compounds are meaningful, we impose two constraints: first, we require that at least $30 \%$ of the compounds satisfying the rule be of type 1 , which is twice the percentage of type 1 compounds in the data and second, we require that the number of type 1 compounds satisfying the rule be at least 25 (one third the number of type 1 compounds in the original data).

Our results, summarized in Table 5, Appendix B, indicate that, for the original dataset, we could not find a region which had a high percentage of type 1 compounds. However, if we remove the correlated features and features that are available for only one or two species, we find one region where 30 of the 67 compounds in the region $(=45 \%)$ are of type 1 . Using ratios or differences of the original scaled or the unscaled properties provides additional insights into regions with a greater than normal percentage of type 1 compounds. These rules also indicate which features are relevant to defining these regions. For example, the occurrence of sg in many of the rules indicates that the space group is an important features for band gap type 1, as predicted in Section 3 .

The rules in Table 5, Appendix B, do not form an exhaustive list; they are the rules we could identify easily in the data. There may be other regions in the data which also have a high percentage of type 1 compounds but are not as easily identifiable. Once we have identified the rules, it may be possible to gain further insights by extracting the compounds which satisfy the rules from the dataset and examining their properties to determine if we can detect any similarities.

\section{Other insights on the data}

We next repeated the analysis with compounds of band gap type 2, 3, and 4 to determine if we could discover rules similar to the ones we found for band gap type 1 compounds. Our results are summarized in Tables 6 - 8, Appendix B. We also make the following observations on these compounds:

- Band gap type 2 compounds: We found only two cases where species "B" has value Y, two with value $\mathrm{Sc}$, and three with $\mathrm{Nb}$.

Of the 486 compounds, 99 (=20.37\%) were of band gap type 2. Thus, to identify useful rules, we required that the number of compounds satisfying the rule should be at least 33 (= one-third of the number of type 2 compounds)), of which, at least $40 \%$ (twice $20.37 \%$ ) were of band gap type 2 . The results are presented in Table 6, Appendix B. 
- Band gap type 3 compounds: Of the 486 compounds, $133(=27.36 \%)$ were of band gap type 3. Thus, to identify useful rules, we required that the number of compounds satisfying the rule should be at least 44 (= one-third of the number of type 3 compounds)), of which, at least $55 \%$ (twice $27.36 \%$ ) were of band gap type 3 . The results are presented in Table 7, Appendix B.

- Band gap type 4 compounds: We found only one case where species "B" has value Sc.

Of the 486 compounds, $178(=36.6 \%)$ were of band gap type 4 . Thus, to identify useful rules, we required that the number of compounds satisfying the rule should be at least 60 (= one-third of the number of type 4 compounds)), of which, at least $72 \%$ (twice $36.6 \%$ ) were of band gap type 4. However, we found that these constraints were too stringent and it was difficult to identify rules that satisfied both constraints. Since there is a higher percentage of type 4 compounds in the data, it may be unreasonable to simply double this percentage to obtain one of the constraints, as we do for other band-gap types. So, we relaxed the constraints, and in Table 8, Appendix B include rules that do not quite meet the original constraints.

These analysis results confirm the relationship between the space group and the band gap type. To explore the issue further, Table 9, Appendix B is a simple count of the number of times a space group results in a particular gap type. The table only lists the space groups which have more than 3 instances. We observe that space group 122 is associated with type 1 or 2 compounds, and space group 198 is linked to type 3 compounds, while space group 2 favors type 4 compounds.

\section{Conclusions and future work}

In this brief report, we discussed the analysis of a data set of ternary compounds in an attempt to determine the properties of the elements that lead to a specific band gap type compound. The original focus was on band-gap type 1 compounds, though the scope of the study was expanded to include band-gap types 2,3 , and 4 as well. The analysis was made difficult by the small size of the dataset, the relatively small number of compounds of certain types, inconsistencies in the dataset, and appropriateness of the representation of the compounds. As a result, we found that traditional data mining techniques, such as classification algorithms, could not be used to atuomatically assign a gap type to a compound based on its composition.

Despite these issues with the quality of the dataset, we wanted to determine if it was possible to gain some insights into what properties of the elements resulted in a specific gap type of compound. We considered alternative representations and determined regions of feature space which had a higher percentage of a specific type of compounds than found in the full dataset. The resulting rules also provide some indication of which features are important.

Based on the analysis, an obvious next step would be to address the inconsistency in the dataset which indicates that additional information about the crystal structure (beyond its space group) is necessary to uniquely determine the band-gap type. Additional data points, prompted perhaps by the rules identified through the analysis, would also be helpful. And finally, the question of how to represent each compound remains an open one; a representation that helps to separate the different band gap types would be ideal. 


\section{Acknowledgment}

This work was performed as part of the ARRA-funded DOE SciDAC-e project, MINDES - Data Mining for Inverse Design, in support of the Center for Inverse Design EFRC. The analysis was done in collaboration with Alberto Franceschetti from NREL, who provided the data and the domain expertise. The analysis of band-gap type 1 was funded by the SciDAC-e program; the analysis of band-gap types 2-4 was unfunded work. I appreciate the support and interest of Alberto Franceschetti, as well as the EFRC Directors, William Tumas and Alex Zunger.

LLNL-TR-577712: This work performed under the auspices of the U.S. Department of Energy by Lawrence Livermore National Laboratory under Contract DE-AC52-07NA27344.

\section{References}

[1] Center for Inverse Design web page, 2012. http://www . centerforinversedesign.org/.

[2] Fang, K.-T., Li, R., And Sudjianto, A. Design and Modeling for Computer Experiments. Chapman and Hall/CRC Press, Boca Raton, FL, 2005.

[3] MINDES: Data Mining for Inverse Design Project web page, 2012. https://computation . llnl.gov/casc/StarSapphire/MINDES.html. 
A List of variables in the dataset 


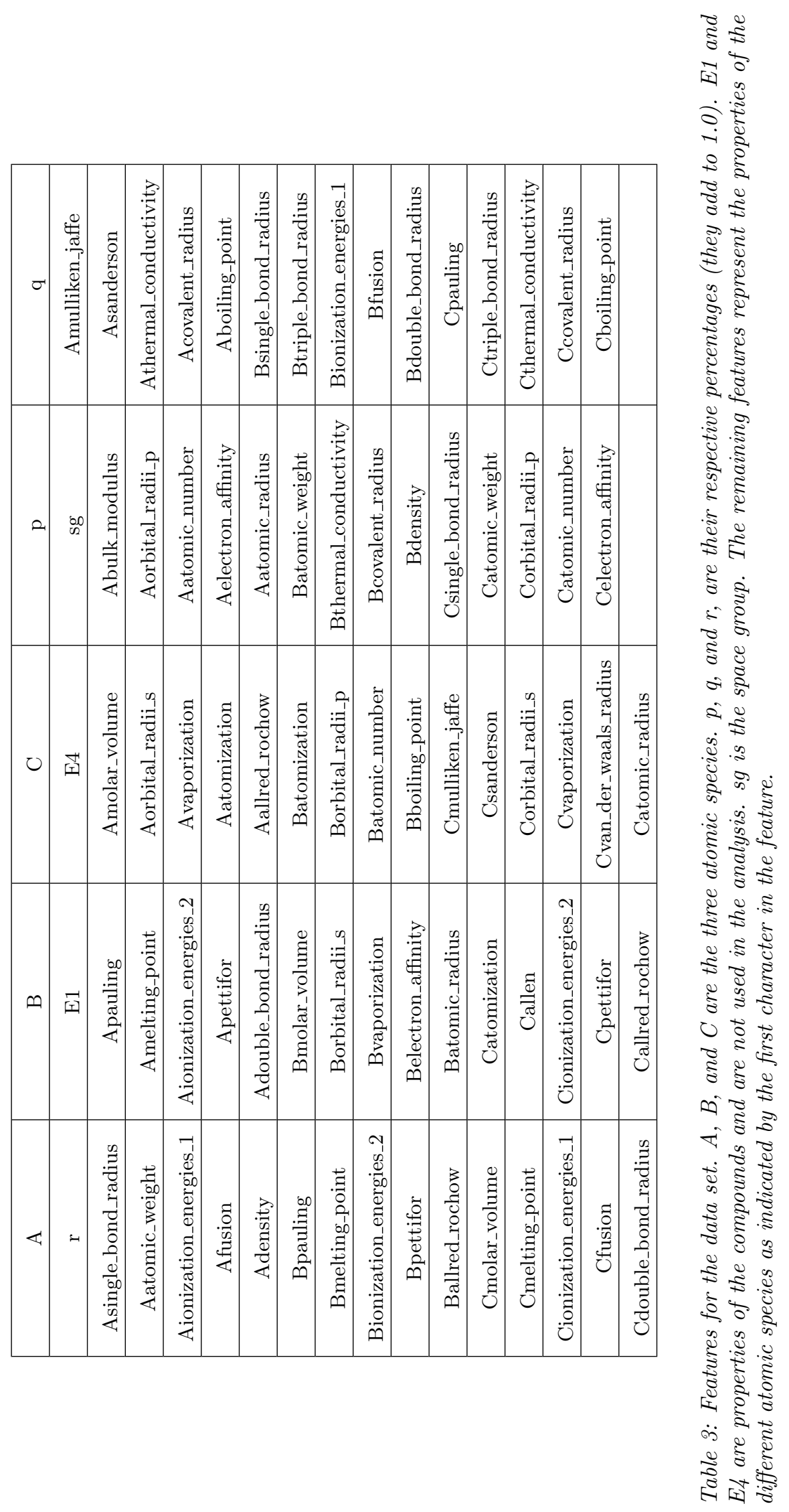




\begin{tabular}{|c|c|c|}
\hline Property for species A & Property for species B & Property for species C \\
\hline Amulliken_jaffe (X) & & Cmulliken_jaffe (X) \\
\hline Asingle_bond_radius & Bsingle_bond_radius & Csingle_bond_radius \\
\hline Apauling & Bpauling & Cpauling \\
\hline Amolar_volume & Bmolar_volume & Cmolar_volume \\
\hline Abulk_modulus (X) & & \\
\hline Asanderson (X) & & Csanderson (X) \\
\hline Aatomic_number & Batomic_number & Catomic_number \\
\hline Aatomic_weight (X) & Batomic_weight (X) & Catomic_weight (X) \\
\hline Amelting_point & Bmelting_point & Cmelting_point \\
\hline Aorbital_radii_s (X) & Borbital_radii_s (X) & Corbital_radii_s (X) \\
\hline Aorbital_radii_p (X) & Borbital_radii_p (X) & Corbital_radii_p (X) \\
\hline Athermal_conductivity & Bthermal_conductivity & Cthermal_conductivity \\
\hline Aionization_energies_1 (X) & Bionization_energies_1 (X) & Cionization_energies_1 (X) \\
\hline Aionization_energies_2 & Bionization_energies_2 & Cionization_energies_2 \\
\hline Avaporization & Bvaporization & Cvaporization \\
\hline Acovalent_radius $(\mathrm{X})$ & Bcovalent_radius $(\mathrm{X})$ & Ccovalent_radius $(\mathrm{X})$ \\
\hline Afusion & Bfusion & Cfusion \\
\hline Apettifor (X) & Bpettifor $(\mathrm{X})$ & Cpettifor (X) \\
\hline Aatomization & Batomization & Catomization \\
\hline Aelectron_affinity & Belectron_affinity & Celectron_affinity \\
\hline Aboiling_point & Bboiling_point & Cboiling_point \\
\hline Adensity & Bdensity & \\
\hline Adouble_bond_radius (X) & Bdouble_bond_radius (X) & Cdouble_bond_radius (X) \\
\hline Aallred_rochow (X) & Ballred_rochow (X) & Callred_rochow (X) \\
\hline \multirow[t]{4}{*}{ Aatomic_radius (X) } & Batomic_radius (X) & Catomic_radius (X) \\
\hline & Btriple_bond_radius (X) & Ctriple_bond_radius (X) \\
\hline & & Callen (X) \\
\hline & & Cvan_der_waals_radius \\
\hline
\end{tabular}

Table 4: Properties for the atomic species A, B, and $C$ organized by species to indicate missing properties: $A$ has 25, $B$ has 23, and $C$ has 26. Several of the properties are correlated to others (correlation coefficient greater than 0.90) and have been marked with an $X$ to indicate they are not being considered further in the analysis. We take a conservative approach, removing a property $Y$ only if it is correlated to another property $Z$ for each of the atomic species for which values are available. See also Table 2. 
B Analysis results 


\begin{tabular}{|c|c|c|c|c|}
\hline Dataset & Rules & $\begin{array}{l}\text { \# results } \\
\text { returned }\end{array}$ & $\begin{array}{l}\text { \#results } \\
\text { of type } 1\end{array}$ & percent \\
\hline $\begin{array}{l}\text { Original scaled data with corre- } \\
\text { lated variables }\end{array}$ & - & - & - & - \\
\hline $\begin{array}{l}\text { Original scaled data, with } \\
\text { cleaned feature set }\end{array}$ & $\begin{array}{l}\text { Bmelting_point }<107.438 \text { and Cioniza- } \\
\text { tion_energies_2 }<1.126 \mathrm{e}+06\end{array}$ & 67 & 30 & $44.8 \%$ \\
\hline \multirow[t]{2}{*}{$\begin{array}{l}\text { Unscaled data, with cleaned fea- } \\
\text { ture set }\end{array}$} & $\begin{array}{l}\mathrm{sg}<141 \text { and CUpauling }<3.44 \text { and } \mathrm{sg} \geq \\
15 \text { and AUsingle_bond_radius }<128\end{array}$ & 43 & 20 & $46.5 \%$ \\
\hline & $\begin{array}{l}\mathrm{sg}<141 \text { and CUpauling }<3.44 \text { and } \mathrm{sg} \geq \\
15 \text { and BUmolar_volume }<18.19\end{array}$ & 120 & 37 & $30.8 \%$ \\
\hline \multirow{4}{*}{$\begin{array}{l}\text { Ratios of original scaled data, } \\
\text { with cleaned feature set }\end{array}$} & BCRmelting_point $<0.581793$ & 124 & 46 & $37.1 \%$ \\
\hline & $\begin{array}{l}\text { BCRmelting_point }<0.581793 \text { and } \mathrm{sg}< \\
126\end{array}$ & 79 & 38 & $48.1 \%$ \\
\hline & $\begin{array}{l}\text { BCRmelting_point }<0.581793 \text { and ACR- } \\
\text { molar_volume }<0.396468\end{array}$ & 50 & 28 & $56 \%$ \\
\hline & $\begin{array}{l}\text { BCRmelting_point }<0.581793 \text { and ACR- } \\
\text { molar_volume }<0.396468 \text { and } \mathrm{sg}<126\end{array}$ & 28 & 23 & $82 \%$ \\
\hline $\begin{array}{l}\text { Differences of original scaled } \\
\text { data, with cleaned feature set }\end{array}$ & $\begin{array}{l}\mathrm{sg}<141 \text { and } \mathrm{sg} \geq 20 \text { and ACDmo- } \\
\text { lar_volume }<-0.731583\end{array}$ & 110 & 44 & $40 \%$ \\
\hline \multirow[t]{2}{*}{$\begin{array}{l}\text { Ratios of unscaled data, with } \\
\text { cleaned feature set }\end{array}$} & $\begin{array}{l}\mathrm{sg}<141 \text { and } \text { ABURmelting-point } \geq \\
1.01359\end{array}$ & 108 & 44 & $40.7 \%$ \\
\hline & $\begin{array}{l}\mathrm{sg}<141 \text { and ABURmelting_point } \geq \\
1.01359 \text { and ABURmolar_volume }<1.027\end{array}$ & 71 & 31 & $43.7 \%$ \\
\hline \multirow[t]{3}{*}{$\begin{array}{l}\text { Differences of unscaled data, } \\
\text { with cleaned feature set }\end{array}$} & $\begin{array}{l}\mathrm{sg}<141 \text { and } \text { ABUDmelting-point } \geq \\
4.11516\end{array}$ & 108 & 44 & $40.7 \%$ \\
\hline & $\begin{array}{l}\mathrm{sg}<141 \text { and ABUDmelting-point } \geq \\
4.11516 \text { and ABUDvaporization }<85300\end{array}$ & 52 & 31 & $59.6 \%$ \\
\hline & $\begin{array}{l}\mathrm{sg}<141 \text { and ABUDmelting_point } \geq \\
4.11516 \text { and ABUDvaporization }<85300 \\
\text { and BCUDelectron_affinity }<-150100\end{array}$ & 34 & 26 & $76.5 \%$ \\
\hline
\end{tabular}

Table 5: Rules for gap type 1 indicating some of the regions where there is a higher percentage of type 1 compounds than in the full dataset. The cleaned data refers to the original data minus the correlated features and features unavailable for all three species. For rules involving the feature sg, a rule of the form "sg<141", should be interpreted to mean the 15 values of sg in Table 9 which have values lower than 141 . 


\begin{tabular}{|c|c|c|c|c|}
\hline Dataset & Rules & $\begin{array}{l}\text { \# results } \\
\text { returned }\end{array}$ & $\begin{array}{l}\text { \#results } \\
\text { of type } 2\end{array}$ & percent \\
\hline $\begin{array}{l}\text { Original scaled data with corre- } \\
\text { lated variables }\end{array}$ & $\begin{array}{l}\text { Bpettifor }<0.308571 \text { and } \mathrm{sg}<143.5 \text { and } \\
\text { Bthermal_conductivity }<10.8 \text { and Amo- } \\
\text { lar_volume } \geq 17.2275\end{array}$ & 40 & 25 & $62.5 \%$ \\
\hline $\begin{array}{l}\text { Original scaled data, with } \\
\text { cleaned feature set }\end{array}$ & $\begin{array}{l}\text { Bmelting_point } \geq 107.438 \text { and Bioniza- } \\
\text { tion_energies_2 }<227843\end{array}$ & 64 & 24 & $37.5 \%$ \\
\hline \multirow[t]{2}{*}{$\begin{array}{l}\text { Unscaled data, with cleaned fea- } \\
\text { ture set }\end{array}$} & $\begin{array}{l}\mathrm{sg}<141 \text { and CUpauling }<3.44 \text { and } \mathrm{sg} \geq \\
15 \text { and AUsingle_bond_radius } \geq 128\end{array}$ & 103 & 40 & $38.8 \%$ \\
\hline & $\begin{array}{l}\mathrm{sg}<141 \text { and } \mathrm{sg} \geq 15 \text { and AUsin- } \\
\text { gle_bond_radius } \geq 128 \text { and BUfusion }< \\
36000\end{array}$ & 132 & 51 & $38.6 \%$ \\
\hline $\begin{array}{l}\text { Ratios of original scaled data, } \\
\text { with cleaned feature set }\end{array}$ & $\begin{array}{l}\text { BCRmelting-point } \geq 0.581793 \text { and } \mathrm{sg}< \\
141 \text { and ABRboiling_point } \geq 0.351574 \text { and } \\
\mathrm{sg} \geq 15\end{array}$ & 107 & 45 & $42.1 \%$ \\
\hline $\begin{array}{l}\text { Differences of original scaled } \\
\text { data, with cleaned feature set }\end{array}$ & $\begin{array}{l}\mathrm{sg}<141 \text { and } \mathrm{sg} \geq 20 \text { and ACDmo- } \\
\text { lar_volume } \geq-0.731583\end{array}$ & 44 & 26 & $59.1 \%$ \\
\hline \multirow[t]{2}{*}{$\begin{array}{l}\text { Ratios of unscaled data, with } \\
\text { cleaned feature set }\end{array}$} & $\begin{array}{l}\mathrm{sg}<141 \text { and } \mathrm{sg} \geq 15 \text { and ABURelec- } \\
\text { tron_affinity } \geq 0.49031 \text { and ABURfusion }< \\
0.645414\end{array}$ & 101 & 41 & $40.6 \%$ \\
\hline & $\begin{array}{l}\mathrm{sg}<141 \text { and } \mathrm{sg} \geq 15 \text { and ABURelec- } \\
\text { tron_affinity } \geq 0.49031 \text { and ABURfusion }< \\
0.338889\end{array}$ & 77 & 37 & $48.0 \%$ \\
\hline \multirow[t]{2}{*}{$\begin{array}{l}\text { Differences of unscaled data, } \\
\text { with cleaned feature set }\end{array}$} & $\begin{array}{l}\mathrm{sg}<141 \text { and } \mathrm{sg} \geq 15 \text { and BCUDpauling } \\
<-0.37 \text { and ABUDatomization }<-190500\end{array}$ & 79 & 36 & $45.6 \%$ \\
\hline & $\begin{array}{l}\mathrm{sg}<141 \text { and } \mathrm{sg} \geq 15 \text { and BCUDpauling } \\
\geq-1.345 \text { and BCUDpauling }<-0.37 \text { and } \\
\text { ABUDatomization }<-190500\end{array}$ & 49 & 31 & $63.3 \%$ \\
\hline
\end{tabular}

Table 6: Rules for gap type 2 indicating some of the regions where there is a higher percentage of type 2 compounds than in the full dataset. The cleaned data refers to the original data minus the correlated features and features unavailable for all three species. For rules involving the feature sg, a rule of the form "sg < 141", should be interpreted to mean the 15 values of sg in Table 9 which have values lower than 141 . 


\begin{tabular}{|c|c|c|c|c|}
\hline Dataset & Rules & $\begin{array}{l}\text { \# results } \\
\text { returned }\end{array}$ & $\begin{array}{l}\text { \#results } \\
\text { of type } 3\end{array}$ & percent \\
\hline $\begin{array}{l}\text { Original scaled data with corre- } \\
\text { lated variables }\end{array}$ & Bpettifor $<0.308571$ and $\mathrm{sg} \geq 143.5$ & 83 & 50 & $60.2 \%$ \\
\hline $\begin{array}{l}\text { Original scaled data, with } \\
\text { cleaned feature set }\end{array}$ & $\begin{array}{l}\text { Bmelting_point } \geq 107.438 \text { and Bioniza- } \\
\text { tion_energies_2 } \geq 227843 \text { and Apauling }< \\
0.4825 \text { and sg i } 141\end{array}$ & 89 & 44 & $49.4 \%$ \\
\hline \multirow[t]{2}{*}{$\begin{array}{l}\text { Unscaled data, with cleaned fea- } \\
\text { ture set }\end{array}$} & $\begin{array}{l}\mathrm{sg} \geq 141 \text { and BUionization_energies_2 }< \\
1.8207 \mathrm{e}+06\end{array}$ & 126 & 67 & $53.2 \%$ \\
\hline & $\begin{array}{l}\mathrm{sg} \geq 141 \text { and BUionization_energies_2 }< \\
1.8207 \mathrm{e}+06 \text { and BUsingle_bond_radius }< \\
163\end{array}$ & 110 & 60 & $54.5 \%$ \\
\hline \multirow[t]{2}{*}{$\begin{array}{l}\text { Ratios of original scaled data, } \\
\text { with cleaned feature set }\end{array}$} & $\begin{array}{l}\text { BCRmelting-point } \geq 0.581793 \text { and } \mathrm{sg} \geq \\
141\end{array}$ & 132 & 65 & $49.2 \%$ \\
\hline & $\begin{array}{l}\text { BCRmelting_point } \geq 0.581793 \text { and } \mathrm{sg} \geq \\
141 \text { and BCRpauling }<0.198643\end{array}$ & 40 & 29 & $72.5 \%$ \\
\hline $\begin{array}{l}\text { Differences of original scaled } \\
\text { data, with cleaned feature set }\end{array}$ & $\begin{array}{l}\mathrm{sg} \geq 141 \text { and BCDthermal_conductivity }< \\
3.99\end{array}$ & 54 & 32 & $59.2 \%$ \\
\hline \multirow[t]{2}{*}{$\begin{array}{l}\text { Ratios of unscaled data, with } \\
\text { cleaned feature set }\end{array}$} & $\begin{array}{l}\mathrm{sg} \geq 141 \text { and ABURmelting_point }< \\
0.848183\end{array}$ & 111 & 59 & $53.1 \%$ \\
\hline & $\begin{array}{l}\mathrm{sg} \geq 141 \text { and ABURmelting-point }< \\
0.848183 \text { and } \mathrm{sg}<225\end{array}$ & 91 & 53 & $58.2 \%$ \\
\hline $\begin{array}{l}\text { Differences of unscaled data, } \\
\text { with cleaned feature set }\end{array}$ & $\begin{array}{l}\text { sg } \geq 141 \text { and ABUDmelting_point }<- \\
207.87\end{array}$ & 99 & 56 & $56.5 \%$ \\
\hline
\end{tabular}

Table 7: Rules for gap type 3 indicating some of the regions where there is a higher percentage of type 3 compounds than in the full dataset. The cleaned data refers to the original data minus the correlated features and features unavailable for all three species. For rules involving the feature sg, a rule of the form "sg < 141", should be interpreted to mean the 15 values of sg in Table 9 which have values lower than 141 . 


\begin{tabular}{|c|c|c|c|c|}
\hline Dataset & Rules & $\begin{array}{l}\text { \# results } \\
\text { returned }\end{array}$ & $\begin{array}{l}\text { \#results } \\
\text { of type } 4\end{array}$ & percent \\
\hline $\begin{array}{l}\text { Original scaled data with corre- } \\
\text { lated variables }\end{array}$ & $\begin{array}{l}\text { Bpettifor } \geq 0.308571 \text { and Aorbital_radii_p } \\
\geq 0.175951\end{array}$ & 135 & 73 & $54.1 \%$ \\
\hline $\begin{array}{l}\text { Original scaled data, with } \\
\text { cleaned feature set }\end{array}$ & Bmelting_point $\geq 107.438$ and $\mathrm{sg}<14$ & 49 & 31 & $63.3 \%$ \\
\hline \multirow[t]{3}{*}{$\begin{array}{l}\text { Unscaled data, with cleaned fea- } \\
\text { ture set }\end{array}$} & $\begin{array}{l}\mathrm{sg} \geq 141 \text { and BUionization_energies_2 } \geq \\
1.8207 \mathrm{e}+06\end{array}$ & 46 & 27 & $58.7 \%$ \\
\hline & $\mathrm{sg}<15$ and CUpauling $<3.44$ & 88 & 40 & $45.5 \%$ \\
\hline & $\begin{array}{l}\mathrm{sg}<15 \text { and CUpauling }<3.44 \text { and AUs- } \\
\text { ingle_bond_radius } \geq 128\end{array}$ & 81 & 37 & $45.7 \%$ \\
\hline \multirow[t]{2}{*}{$\begin{array}{l}\text { Ratios of original scaled data, } \\
\text { with cleaned feature set }\end{array}$} & $\begin{array}{l}\text { BCRmelting_point } \geq 0.58179 \text { and } \mathrm{sg}<141 \\
\text { and ABRboiling_point }<0.351574\end{array}$ & 74 & 44 & $59.5 \%$ \\
\hline & $\begin{array}{l}\text { BCRmelting_point } \geq 0.58179 \text { and } \mathrm{sg} \geq 141 \\
\text { and BCRpauling } \geq 0.198643\end{array}$ & 94 & 43 & $45.7 \%$ \\
\hline \multirow{3}{*}{$\begin{array}{l}\text { Differences of original scaled } \\
\text { data, with cleaned feature set }\end{array}$} & $\operatorname{sg}<20$ & 160 & 76 & $47.5 \%$ \\
\hline & $\begin{array}{l}\mathrm{sg}<20 \text { and ABDionization_energies_2 }< \\
124988\end{array}$ & 52 & 36 & $69.2 \%$ \\
\hline & $\begin{array}{l}\mathrm{sg} \geq 166 \text { and BCDthermal_conductivity } \geq \\
3.99\end{array}$ & 96 & 48 & $50.0 \%$ \\
\hline \multirow{3}{*}{$\begin{array}{l}\text { Ratios of unscaled data, with } \\
\text { cleaned feature set }\end{array}$} & $\mathrm{sg}<15$ & 117 & 53 & $45.3 \%$ \\
\hline & $\begin{array}{l}\text { sg }<15 \text { and ACURelectron_affinity }< \\
0.422695\end{array}$ & 96 & 45 & $46.9 \%$ \\
\hline & $\begin{array}{l}\text { sg } \geq 141 \text { and ABURmelting_point } \geq \\
0.848183\end{array}$ & 61 & 35 & $57.4 \%$ \\
\hline \multirow[t]{2}{*}{$\begin{array}{l}\text { Differences of unscaled data, } \\
\text { with cleaned feature set }\end{array}$} & $\begin{array}{l}\text { sg } \geq 141 \text { and ABUDmelting-point } \geq- \\
207.87\end{array}$ & 73 & 39 & $53.4 \%$ \\
\hline & $\mathrm{sg}<15$ and BCUDatomization $<559000$ & 116 & 53 & $45.7 \%$ \\
\hline
\end{tabular}

Table 8: Rules for gap type 4 indicating some of the regions where there is a higher percentage of type 4 compounds than in the full dataset. The cleaned data refers to the original data minus the correlated features and features unavailable for all three species. For rules involving the feature sg, a rule of the form "sg < 141", should be interpreted to mean the 15 values of sg in Table 9 which have values lower than 141. 


\begin{tabular}{|c|c|c|c|c|c|}
\hline SG value & Type 1 & Type 2 & Type 3 & Type 4 & Total \\
\hline 2 & 2 & 1 & 3 & 16 & 22 \\
\hline 11 & 1 & 0 & 5 & 1 & 7 \\
\hline 12 & 0 & 7 & 4 & 16 & 27 \\
\hline 14 & 8 & 6 & 16 & 18 & 48 \\
\hline 15 & 3 & 11 & 2 & 19 & 35 \\
\hline 19 & 0 & 2 & 2 & 4 & 8 \\
\hline 31 & 4 & 2 & 1 & 0 & 7 \\
\hline 33 & 10 & 2 & 3 & 1 & 16 \\
\hline 55 & 1 & 0 & 0 & 3 & 4 \\
\hline 61 & 0 & 3 & 0 & 1 & 4 \\
\hline 62 & 3 & 16 & 9 & 9 & 37 \\
\hline 63 & 0 & 3 & 0 & 2 & 5 \\
\hline 121 & 2 & 1 & 1 & 1 & 5 \\
\hline 122 & 18 & 6 & 0 & 1 & 25 \\
\hline 140 & 0 & 3 & 0 & 3 & 6 \\
\hline 148 & 0 & 2 & 1 & 4 & 7 \\
\hline 161 & 0 & 1 & 1 & 5 & 7 \\
\hline 166 & 1 & 5 & 11 & 18 & 35 \\
\hline 194 & 1 & 3 & 9 & 11 & 24 \\
\hline 198 & 3 & 1 & 12 & 0 & 16 \\
\hline 215 & 0 & 0 & 5 & 3 & 8 \\
\hline 216 & 5 & 0 & 3 & 0 & 8 \\
\hline 217 & 0 & 5 & 2 & 0 & 7 \\
\hline 225 & 2 & 1 & 5 & 16 & 24 \\
\hline 227 & 0 & 0 & 3 & 3 & 6 \\
\hline
\end{tabular}

Table 9: Count (if total > 3) of different band types for each space group. 